Tropical Journal of Pharmaceutical Research May 2017; 16 (5): 1097-1104

ISSN: $1596-5996$ (print); 1596-9827 (electronic)

(C) Pharmacotherapy Group, Faculty of Pharmacy, University of Benin, Benin City, 300001 Nigeria.

All rights reserved.

Available online at http://www.tjpr.org

Original Research Article

http://dx.doi.org/10.4314/tjpr.v16i5.18

\title{
Cardioprotective effect of Shenxiong glucose injection on acute myocardial infarction in rats via reduction in myocardial intracellular calcium ion overload
}

\author{
Zhi-Hua Wang ${ }^{1}$, Jian-Hao Pan ${ }^{1}$, Xian-Peng $\mathrm{Ma}^{2}$, Xiao-Yun $\mathrm{Xu}^{1}$, Wen-Hui $\mathrm{Yu}^{1}$, \\ Wen-Juan $\mathrm{Fu}^{1}$, Jian $\mathrm{Ke}^{1}$, Chang-Qiong $\mathrm{Bi}^{2}$, Wei $\mathrm{Wei}^{2}$, Qu Zhao ${ }^{2}$, Feng Wang ${ }^{1}$, \\ Dan Tang ${ }^{1}$, Kaihe $\mathrm{Ye}^{1}$, Zhixian $\mathrm{Yi}^{3}$ and Hong $\mathrm{Nie}^{1 *}$ \\ ${ }^{1}$ Guangdong Province Key Laboratory of Pharmacodynamics Constituents of TCM and New Drugs Research, College of \\ Pharmacy, Jinan University, 601 Huangpu Avenue West, Guangzhou, 510632, China, ${ }^{2}$ Guizhou Jingfeng Injection Co. Ltd, No. \\ 158 Gaoxin Road Wudang District, Guiyang, 550018, China, ${ }^{3}$ School of Information Studies, Charles Sturt University, Locked \\ Bag 588, Boorooma Street, Wagga Wagga, NSW 2678, Australia
}

*For correspondence: Email: tnieh@jnu.edu.cn; Tel: +86 2085222810

Sent for review: 19 December 2016

Revised accepted: 19 April 2017

\begin{abstract}
Purpose: To explore the cardioprotective effects and potential mechanisms of Shenxiong Glucose Injection (SGI) in rat acute myocardial infarction (AMI).

Methods: AMI model was created by ligating left anterior descending coronary artery. After 7 days' consecutive intravenous administration of SGI, serum samples were used to conduct biochemical analysis while hearts were excised and processed for infraction size, enzyme activity, histopathology and qPCR studies. Intracellular $\mathrm{Ca}^{2+}\left\{\left(\mathrm{Ca}^{2+}\right)\right.$ i\} overload in $\mathrm{H} 9 \mathrm{c} 2$ cells was measured by laser scanning confocal microscope (LSCM).

Results: In AMI rats, pretreatment with SGI significantly ameliorated myocardial histopathologic damage. It exerted cardioprotective effect by decreasing myocardial infarct size, electrocardiogram (ECG) ST segment elevation, and CK, cTnl, BNP levels in serum. In addition, SGI significantly decreased calmodulin (CaM) and calmodulin-dependent protein kinase II (CaMK II) mRNA expression, but increased $\mathrm{Ca}^{2+}-\mathrm{Mg}^{2+}-$ ATPase and Na+-K+-ATPase activities in myocardium. In doxorubicin (DOX)induced H9c2 cells injury model, SGI reversed $\left(\mathrm{Ca}^{2+}\right)$ i overload to protect cells.

Conclusion: The results demonstrate SGI exerts cardioprotective effect by decreasing myocardial infarct size, restoring ST segment and reversing $\left(\mathrm{Ca}^{2+}\right) i$ overload. It suggests that SGI may be a new clinical candidate to treat myocardial infarction.
\end{abstract}

Keywords: Shenxiong glucose injection, Tanshinol, Ligustrazine, Myocardial infarction, Intracellular $\mathrm{Ca}^{2+}$ overload, Calmodulin, Calmodulin-dependent protein kinase II

Tropical Journal of Pharmaceutical Research is indexed by Science Citation Index (SciSearch), Scopus, International Pharmaceutical Abstract, Chemical Abstracts, Embase, Index Copernicus, EBSCO, African Index Medicus, JournalSeek, Journal Citation Reports/Science Edition, Directory of Open Access Journals (DOAJ), African Journal Online, Bioline International, Open-J-Gate and Pharmacy Abstracts

\section{INTRODUCTION}

Ischemic heart disease, commonly called coronary artery disease, is a disease characterized by reduced blood supply to the heart. It has been the top one cause of life loss each year all over the world, bringing about 8.14 million fatalities in 2013 up from 5.74 million fatalities in 1990. It has been a tough global health problem to be solved according to the data analysis of cause-specific mortality for 240 causes of death during 1990 - 2013[1]. Although kinds of drugs such as aspirin, thrombolysis agents, $\beta$ receptor blockers and ACE inhibitors 
have been used to treat AMI [2,3], AMI is still one of the major cause of ischemic heart diseases, and with high rate of morbidity and mortality [4]. Therefore, the safer and more effective drugs still need to be explored for clinical use.

SGl is also known as Bai Se Tong, and its components are originated from danshen (Salvia miltiorrhiza Bge.) and chuanxiong (Ligusticum chuanxiong Hort.). It has been widely used in cerebral ischemia disease and other ischemic diseases in Asia. Tanshinol and ligustrazine hydrochloride, the active ingredients of SGI, have been confirmed to exhibit powerful protective effects on cardio-cerebrovascular disease in vitro and in vivo, and they have shown various pharmacological activities such as anti-oxidation, anti-apoptosis, and anticoagulation in the treatment of ischemic and infarction disease [57].

Previous studies have shown that SGI possesses protective effects on cerebral, and its potential mechanisms are involved in antiinflammation, anti-oxidation and anticoagulation [8]. And what's more, clinical applications and animal experimental studies have demonstrated that there are seldom adverse effects after administration of SGI [8,9]. However, the cardioprotective effect and mechanisms of SGI has been rarely reported.

The main objective of our study is to investigate the cardioprotective effects and potential mechanisms of SGI on AMI injury.

\section{EXPERIMENTAL}

\section{Materials}

SGI was provided by Guizhou Jingfeng Injection Co., Ltd. (Guiyang, China). Panax notoginseng saponins (PNS) was bought from Guangxi Wuzhou Pharmaceutical Co., Ltd. (Wuzhou, China). Kits for creatine kinase (CK), $\mathrm{Ca}^{2+}-\mathrm{Mg}^{2+}$ ATPase and $\mathrm{Na}^{+}-\mathrm{K}^{+}$-ATPase were purchased from Nanjing Jiancheng Bioengineering Institute (Nanjing, China). Cardiac troponin I (cTnl) and brain natriuretic peptide (BNP) Elisa kits were obtained from Wuhan Cusabio Biotech Co., Ltd. (Wuhan, China). Fluo-3-AM was supplied by Beijing Fanbo biochemical pharmaceutical Co., Ltd. (Beijing, China). N-acetylcysteine (NAC) and DOX were provided by MP biochemical (California, USA). And kits for PrimeScript ${ }^{T M}$ RT reagent Kit (Perfect Real Time) and SYBR® Premix Ex $\mathrm{Taq}^{\mathrm{TM}}$ II (Tli RNaseH Plus) were gained from Takara(Shenyang, China). H9c2 cells were got from the Cell Bank of the Chinese Academy of Sciences (Shanghai, China).

\section{Animals and AMI injury model}

Adult specific pathogen free (SPF) male Sprague-Dawley (SD) rats $(180-220 \mathrm{~g}$, certificate: NO. SCXK (Guangdong) 2013-0034) were obtained from the Medical Laboratory Animal Research Center of Guangdong Province. All rats were kept in a SPF level laboratory animal room in the institution of Laboratory Animal Science of Jinan University with normal temperature and $12 \mathrm{~h}$ light-dark cycle. Rats were provided with standard laboratory diet and water. The experiments were approved by the Committee on Animal Care of Jinan University (no. 20140615231359) and were performed according to the instructions of the National Institute of Health (OLAW/NIH 2002) [10].

SD rats were randomly assigned into 6 groups with 14 rats in each group: sham-operated (control), AMI, PNS (22.30 mg/kg), Low-dose SGI $(0.714 \mathrm{mg} / \mathrm{kg}$ tanshinol and ligustrazine hydrochloride $3.57 \mathrm{mg} / \mathrm{kg}$ ), Middle-dose SGI (3.57 $\mathrm{mg} / \mathrm{kg}$ tanshinol and ligustrazine hydrochloride $17.85 \mathrm{mg} / \mathrm{kg}$ ), High-dose SGI (tanshinol $17.85 \mathrm{mg} / \mathrm{kg}$ and ligustrazine hydrochloride $89.25 \mathrm{mg} / \mathrm{kg}$ ). PNS has been widely used in cerebral and myocardial ischemia disease in clinics. In this study, it was treated as a positive control. The rats of control and AMI groups were administered with $5 \%$ of glucose injection via caudal vein for 7 days consecutively, while the rest of rats were administered for 7 days respectively with the drugs accordingly.

AMI injury model was created according to our previous study with slight modifications [11]. The rats were anesthetized with $25 \%$ of urethanum (1 $\mathrm{g} / \mathrm{kg}$, intraperitoneally). Following intubation and artificial ventilation, the surgical operation was performed to expose heart. The heart was rapidly exposed and the left anterior descending coronary artery was ligated with a suture, control group just exposed heart without ligating. Electrocardiography was recorded by ECG2206B system (Nanjing Hengteng electronic technology Co., Ltd., Nanjing, China) before and 5, 15, 30, $60,120 \mathrm{~min}$ after the surgery, the ECG recording speed was $50 \mathrm{~mm} / \mathrm{s}$ at a voltage of $10 \mathrm{~mm} / \mathrm{mV}$. The ST segment elevation of limb lead (II) ECG was used to determine the AMI injury. After the last time ECG recording, blood samples were collected from abdominal aorta to separate out serum by centrifugation at $3000 \mathrm{rpm}$ for $10 \mathrm{~min}$ for further biochemical analysis. Successively, the hearts of all rats were got and performed for infraction size, pathology, and qPCR researches. 


\section{Measurement of serum biomarker of AMI}

The serum content of CK, cTn-I and BNP was measured by corresponding commercial enzyme-linked immunosorbent assay kits described above. Spectrophotometry method was used to detect the kits by multi-detection microplate reader (Synergy ${ }^{\mathrm{TM}}$ HT, BioTek, USA). All protocols were performed according to the kit manufacture recommendations.

\section{Histopathological analysis}

Left ventricular heart tissues were fixed in paraformaldehyde and embedded in paraffin, and then slice into serial very thin pieces using microtome. The pieces were stained with $\mathrm{H} \& \mathrm{E}$ to observe the change of myocardium $s$ by a microscope (Olympus CX31, Japan).

\section{Determination of infarct size}

The infarct size was determined as previously described [11]. The TTC-stained areas (red staining) and TTC-stained negative areas (myocardial infarction) were isolated and the infarct size was expressed as the percentage of the myocardial weight.

\section{Determination of $\mathrm{Ca}^{2+}-\mathrm{Mg}^{2+}-\mathrm{ATPase}$ and $\mathrm{Na}^{+}-$ $\mathrm{K}^{+}$-ATPase activities}

Myocardial tissues were weighed and made into homogenates with normal saline. After centrifugation, the supernatant was obtained and used to determinate the protein concentration and the enzyme activity. The procedure used were strictly in accordance with the instruction of ATPase assay kits and Bradford Protein Assay Kit.

\section{Measurement of mRNA expression of CaM and CaMK II}

RNA was obtained from the myocardial tissues. Myocardial tissues were grinded with liquid nitrogen. Later, mRNA was extracted by RNA Trizol reagent and RNA integrity was determined by $1 \%$ of agarose gel. cDNAs were reversely transcribed using each RNA sample and were amplified by PCR. The primers sequences for rat CaM were: F:5' GATAAGGATGGCAATGGC TACA3' R:5'CGATGTCTGCTTCCCTGATCAT3', CaMK II were: F:5'GTGATGGGAAGTGGCA GAATA3' R: 5'CGTGGCACTGTTGACAATTAG $A 3^{\prime}$ and $\beta$-actin were: $F: 5$ 'CCTGTGGCA TCCATGAAACTAC3' R: 5'CTTCTGCATCCTG TCAGCAAT3'. $\beta$-actin was used as a reference gene. The mRNA relative expression levels of
CaM and CaMK /I were normalized to $\beta$-actin and calculated using the $2^{-\Delta \Delta \mathrm{CT}}$ method.

\section{Measurement of intracellular calcium concentration}

Changes in $\left(\mathrm{Ca}^{2+}\right)$ i concentration were measured by $\mathrm{Ca}^{2+}$ sensitive fluorescent indicator Fluo-3-AM and LSCM (LSM 510 META, Zeiss, Germany). $\mathrm{H} 9 \mathrm{c} 2$ cells were cultivated with or without SGI $(0.08,0.28$ and $0.48 \mu \mathrm{mol} / \mathrm{L}$, calculated by ligustrazine hydrochloride), $\mathrm{NAC}(1 \mathrm{mmol} / \mathrm{L})$ for 2 $\mathrm{h}$ except control group, then added $1 \mu \mathrm{mol} / \mathrm{L}$ DOX cultivated for $48 \mathrm{~h}$. The cells were quickly flushed and incubated with $5 \mu \mathrm{M}$ Fluo-3-AM in a glass-bottom dish for $30 \mathrm{~min}$ at $37^{\circ} \mathrm{C}$ and quickly flushed three times with PBS buffer and incubated for $15 \mathrm{~min}$. $\left(\mathrm{Ca}^{2+}\right) \mathrm{i}$ was measured as described previously[12]. Fluorescence was excited at a wavelength of $490 \mathrm{~nm}$ and emitted light was observed at $525 \mathrm{~nm}$. Zeiss LSM image browser, a data processing system, was used to calculate intracellular fluorescence intensity.

\section{Statistics}

All numerical results are presented as mean \pm SEM and statistical significance was analyzed with one-way analysis of variance (ANOVA) using SPSS 17.0 software. Differences were considered significant at $p<0.05$.

\section{RESULTS}

SGI ameliorates ECG and decreases biomarkers of AMI injury in AMI rats

The myocardial injury can lead to abnormal ST segment change, so ECG can reflect the myocardial injury directly. In our present study, AMI injury resulted in significant ST segment elevation in the AMI group, which demonstrated that the AMI injury model of rats was successfully established. In addition, compared with AMI group, the ST segments of other groups were significantly reduced in a dose and timedependent manner (Figure 1A). More importantly, the ST segment elevation of PNS and SGI $(\mathrm{H})$ was significantly reduced within 120 min of the experiment $(p<0.01$ or 0.05 ). The ECG of rats at $120 \mathrm{~min}$ are shown in Figure 1B. What's more, we also measured the content of CK, cTnl and BNP to examine the extent of myocardial damage and the protective effects of SGI. As shown in Table 1, the CK, cTnl and BNP contents of AMI group rats were higher than those for control group $(p<0.05)$. However, after being treated with SGI or PNS, the serum CK, $c T n l$ and BNP contents were significantly decreased $(p<0.01$ or 0.05$)$. 

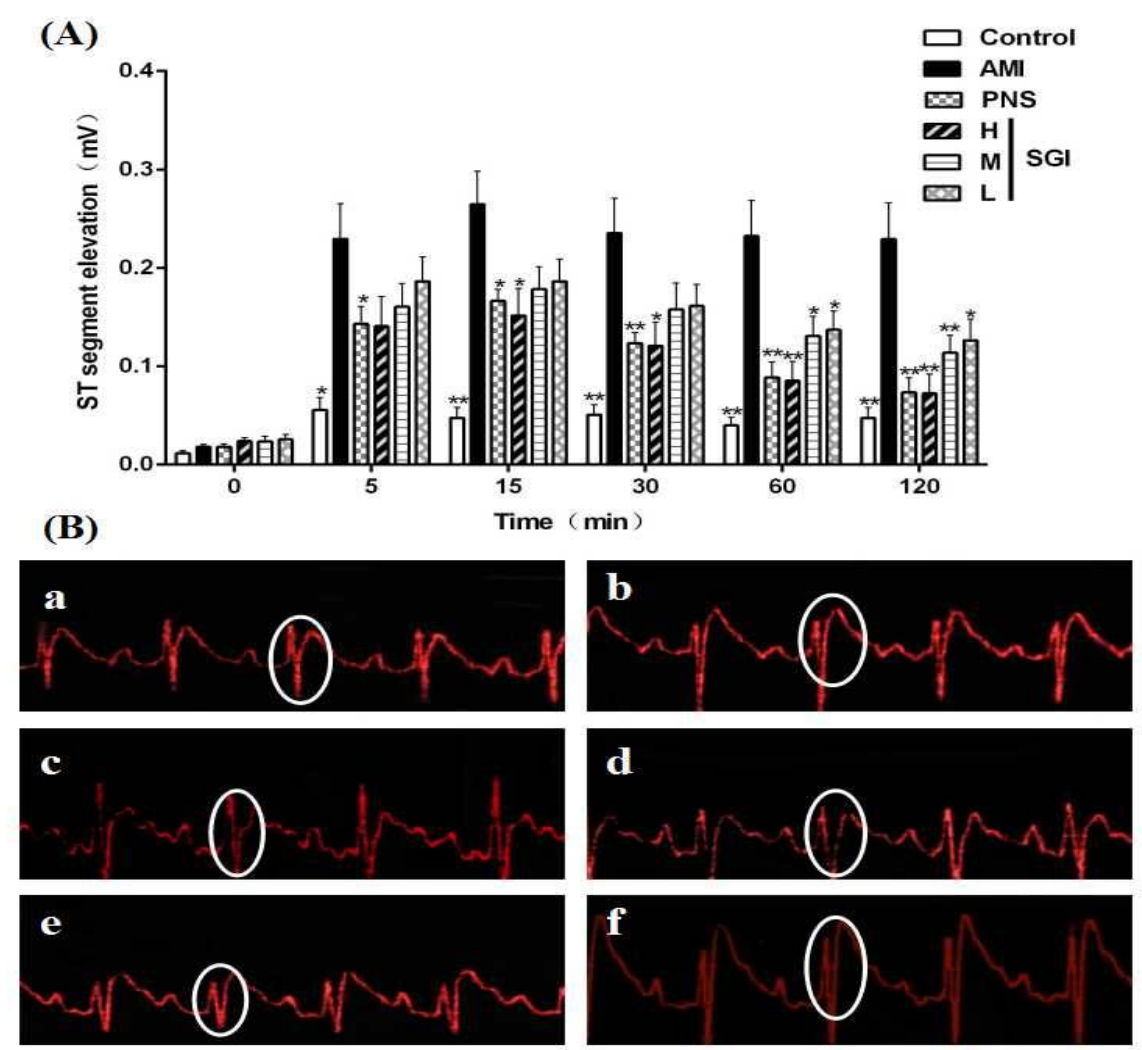

Figure 1: Effect of SGI on ECG in AMI injury rats. ST segment elevation in AMI injury rats during 120 min (A). ECG of AMI injury rats at 120 min (B). Compared with AMl group; $p<0.05,{ }^{* *} p<0.01,(n \geq 12)$. The letters a to $f$ are represented for control group, AMI group, PNS group, SGI(H) group, SGI(M) group and SGI(L) group, respectively

Table 1: Effect of SGI on serum CK, cTnl and BNP content in AMI injury rats

\begin{tabular}{lccc}
\hline Group & CK (serum, U/mL) & cTnl (serum, $\boldsymbol{\mu g} / \mathbf{L})$ & BNP $($ serum, $\mathbf{~ g} / \mathbf{m L})$ \\
\hline Control & $0.90 \pm 0.06$ & $217.21 \pm 26.73$ & $1088.32 \pm 89.14$ \\
AMI & $1.11 \pm 0.07$ & $293.66 \pm 24.16$ & $1364.94 \pm 79.80$ \\
PNS & $0.85 \pm 0.07^{*}$ & $317.23 \pm 42.13$ & $1331.29 \pm 134.82$ \\
SGI (H) & $0.82 \pm 0.08^{*}$ & $168.11 \pm 13.19^{*}$ & $1259.32 \pm 131.70$ \\
SGI (M) & $0.88 \pm 0.06^{*}$ & $176.66 \pm 35.73^{*}$ & $1081.37 \pm 111.03^{*}$ \\
SGI (L) & $0.72 \pm 0.06^{*}$ & $214.19 \pm 35.80$ & $996.14 \pm 47.40^{*}$ \\
\hline
\end{tabular}

Compared with AMI group, $p<0.05, " p<0.01,(n \geq 7)$

\section{SGI decreases infarct size and protects myocardium structure in AMI rats}

As shown in Figure 2B, myocardial infarct size in AMI group was significantly larger than that of control group $(p<0.01)$. When treated with SGI or PNS, myocardial infarct size was significantly reduced $(p<0.01$ or $p<0.05)$, except SGI $(L)$. TTC staining of myocardium intuitively revealed the degree of AMI injury of rats (Figure 2A, a-f). Meanwhile, histopathological analysis showed that myocardium structure of control group rats were normal with clear boundaries, but AMI injury in AMI group caused myocardium to be remarkably loose and disordered. Rats treated with PNS or SGI can ameliorate irregular arrangement of myocardium (Figure 2C, a-f).

\section{SGI regulates $\mathrm{Ca}^{2+}$ related enzyme activity and mRNA expression}

As shown in Table 2, rats suffered from AMI injury induced to significant decline of the $\mathrm{Ca}^{2+}$ $\mathrm{Mg}^{2+}$-ATPase and $\mathrm{Na}^{+}-\mathrm{K}^{+}$-ATPase activities $(p<$ $0.01)$. PNS and SGI pretreatment protected their activities decline from AMI injury $(p<0.01$ or $p<$ 0.05). Meanwhile, CaM and CaMK // expressions were significantly improved in AMI injury rats $(p<$ $0.01)$. On the contrary, pretreatment of PNS and SGI significantly decreased CaM and CaMK II mRNA expression in some degree $(p<0.01$ or $p$ $<0.05)$.

\section{SGI decreases DOX-induced $\mathrm{H} 9 \mathrm{c2}$ cells $\left(\mathrm{Ca}^{2+}\right)$ i overload}

In order to confirm the effect of SGI on $\left(\mathrm{Ca}^{2+}\right) \mathrm{i}$ 
overload, we investigated it in DOX-induced H9c2 cells injury model. Intuitively, the fluorescence intensity of DOX group was more severe than other groups (Figure $3 \mathrm{~A}$ ). Then, 35 cells were randomly selected in each group to calculate the relative intracellular calcium concentration. The results show that $\left(\mathrm{Ca}^{2+}\right) \mathrm{i}$ of the DOX group was higher than that of the control group $(p<0.01)$. Similarly, $\left(\mathrm{Ca}^{2+}\right)$ i of NAC group, all the SGI groups had a significantly decrease compared with DOX group $(p<0.01)$ (Figure 3B).
(A)

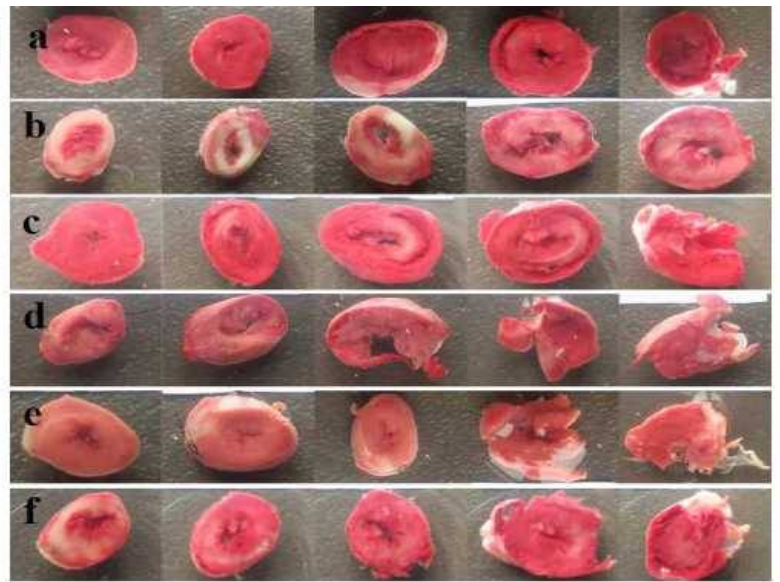

(C)
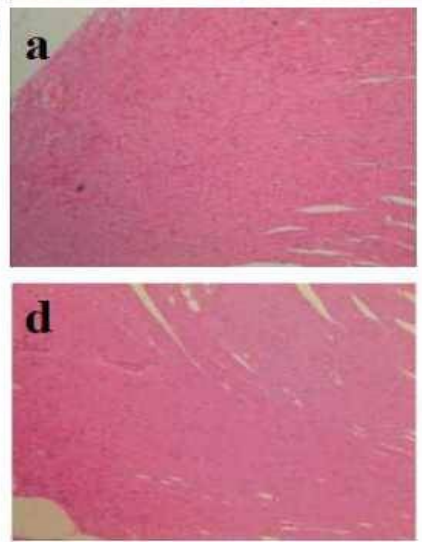
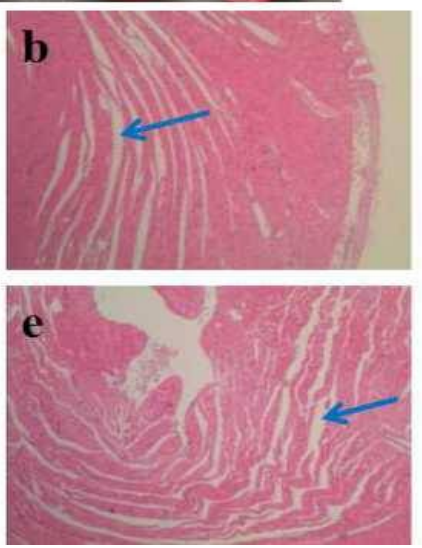

(B)
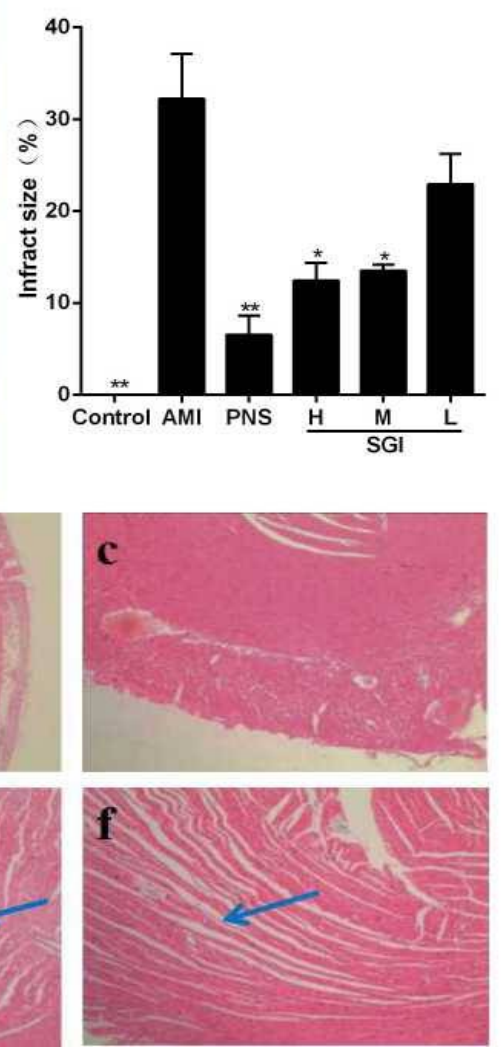

Figure 2: Effect of SGI on infarct size and microscopic observation of cardiac tissue. The myocardial infarct size was measured by TTC staining (A). Quantitative analysis the myocardial infarct size of the AMl injury rats $(B)$. Myocardium stained with H\&E to observe myocardial injury (C) ( $\times 100)$. Compared with AMl group; $p<0.05,{ }^{* *} p<$ $0.01,(n \geq 4)$. The letters a to $f$ are represented as describe above

Table 2: Effect of SGI on $\mathrm{Ca}^{2+}-\mathrm{Mg}^{2+}-\mathrm{ATPase}, \mathrm{Na}^{+}-\mathrm{K}^{+}-\mathrm{ATPase}$ activities and CaM , CaMK II mRNA relative expression in AMI injury rats

\begin{tabular}{|c|c|c|c|c|}
\hline Group & $\begin{array}{c}\mathrm{Na}^{+}-\mathrm{K}^{+}-\mathrm{ATPase} \\
(\mu \mathrm{molPi} / \mathrm{mgprot} / \mathrm{h})\end{array}$ & $\begin{array}{l}\mathrm{Ca}^{2+}-\mathrm{Mg}^{2+}-\mathrm{ATPase} \\
\text { ( } \mathrm{mol} \mathrm{mi} / \mathrm{mgprot} / \mathrm{h})\end{array}$ & CaM & CaMK II \\
\hline Control & $1.93 \pm 0.17^{*}$ & $2.01 \pm 0.14$ & $0.29 \pm 0.02$ & $0.66 \pm 0.03$ \\
\hline AMI & $0.89 \pm 0.17$ & $1.14 \pm 0.09$ & $1.00 \pm 0.24$ & $1.00 \pm 0.03$ \\
\hline PNS & $1.69 \pm 0.14$ & $1.85 \pm 0.16$ & $0.35 \pm 0.09 "$ & $0.80 \pm 0.01$ \\
\hline SGI(H) & $1.66 \pm 0.13^{n}$ & $1.84 \pm 0.22$ & $0.35 \pm 0.02$ & $0.80 \pm 0.17$ \\
\hline SGI(M) & $1.38 \pm 0.14^{\pi *}$ & $1.57 \pm 0.24^{\pi}$ & $0.65 \pm 0.03^{\mathrm{x}}$ & $1.00 \pm 0.08$ \\
\hline SGI(L) & $1.33 \pm 0.09^{\pi x}$ & $1.54 \pm 0.12^{\pi}$ & $0.75 \pm 0.07^{\pi x}$ & $1.01 \pm 0.02$ \\
\hline
\end{tabular}

Compared with AMI group, $p<0.05, " p<0.01,(n=4)$

\section{DISCUSSION}

SGI, consisted of two effective ingredients ligustrazine hydrochloride and tanshinol, has shown multiple effects on cerebral disease, but the cardioprotective effect and mechanisms of SGI has been rarely reported [8]. The objective of our present study is to examine whether SGI plays a protective role in AMI injury and explore its potential mechanisms.

ECG and the content of CK, cTnl and BNP have been widely used as biomarkers of myocardial injury. Consistent with the previous studies [11], 
(A)

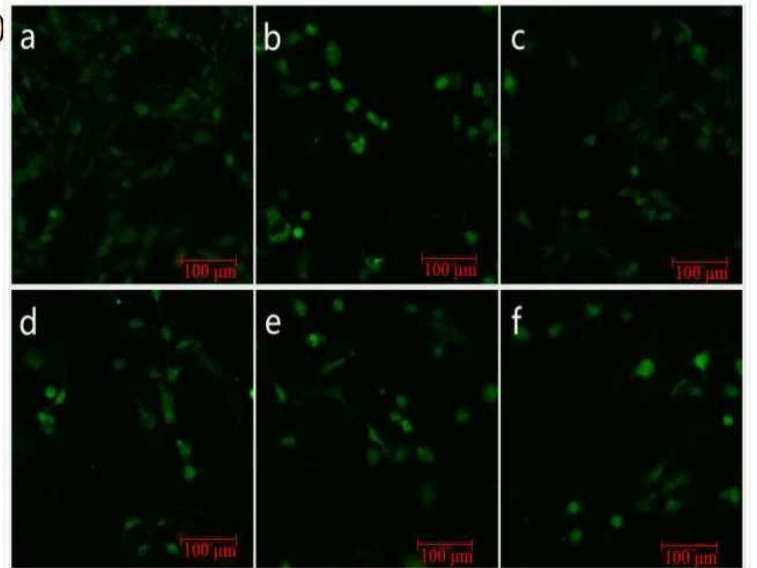

(B)

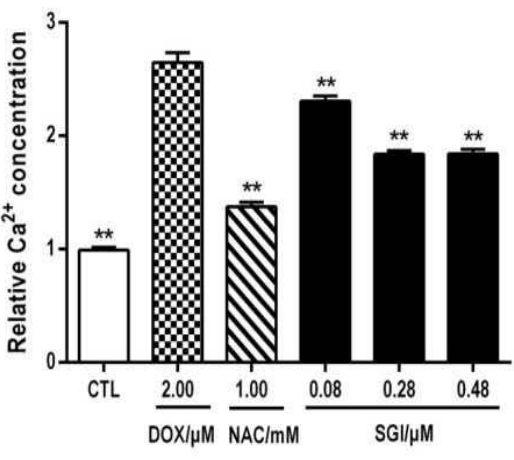

Figure 3: Treatment of SGI inhibited DOX-induced $\left(\mathrm{Ca}^{2+}\right) \mathrm{i}$ overload. $\left(\mathrm{Ca}^{2+}\right) \mathrm{i}$ was determined with Fluo-3-AM probe by LSCM (scale bar: $100 \mu \mathrm{m})(\mathrm{A})$. Quantitative analysis of relative $\left(\mathrm{Ca}^{2+}\right)$ i concentration (B). Compared with DOX group, $p<0.05,{ }^{* *} p<0.01$. a: Control group, b: DOX group, c: 1 mmol/L NAC group, d: $0.08 \mu \mathrm{mol} / \mathrm{L}$ SGI group, e: $0.28 \mu \mathrm{mol} / \mathrm{L}$ SGI group, f: $0.48 \mu \mathrm{mol} / \mathrm{L}$ SGI group

we observed significant increase of $\mathrm{CK}, \mathrm{cTnl}$ and BNP content and elevation of typical ECG ST segment in rats subjected to acute myocardial infarction. The pretreatment of SGI can decline the high level of CK, cTnl, BNP and the elevation of ECG ST segment. Meanwhile, we also found that the area at risk was significantly reduced and myocardial structure was better-preserved in SGI pretreatment rats. All in all, these results have demonstrated the cardioprotective effects of SGI.

As an important second messenger, $\mathrm{Ca}^{2+}$ signal is a leading mediator in the management of many physiological and cellular activities, such as muscle contraction, metabolism, cell necrosis, apoptosis and autophagy and so on $[13,14]$. In ischemic and infarcted myocardium, the deficiency of ATP triggers the lower activity of $\mathrm{Ca}^{2+}-\mathrm{Mg}^{2+}-$ ATPase and $\mathrm{Na}^{+}-\mathrm{K}^{+}-$ATPase, which induces $\mathrm{Na}^{+}$overload and secondary $\mathrm{Ca}^{2+}$ influx. $\left(\mathrm{Ca}^{2+}\right) \mathrm{i}$ overload can cause arrhythmia and necrosis during myocardial infarction [15]. The overwhelming $\left(\mathrm{Ca}^{2+}\right) \mathrm{i}$ combines with $\mathrm{CaM}$ and further activates CaMK II, which can regulate $\mathrm{Ca}^{2+}$ concentration by changing the function of ryanodine receptor (RyR), phospholamban (PLB) and $L$ type calcium channel (LTCC) $[16,17]$. On the one hand, CaMK II can improve the $\left(\mathrm{Ca}^{2+}\right) \mathrm{i}$ concentration by prolonging the opening time of RyR and LTCC. On the other hand, it can phosphorylate PLB, further relieve the inhibition on $\mathrm{Ca}^{2+}$-ATPase and enhance the $\mathrm{Ca}^{2+}$ reuptake of the sarcoplasmic reticulum (SR). As outlined above, CaMK II, as a significant regulator of $\left(\mathrm{Ca}^{2+}\right) \mathrm{i}$, has been confirmed as a therapeutic target in new drug research and development, and studies have demonstrated that blocking CaMK II with inhibitor KN93 can significantly diminish ischemic contracture in vivo, prevent cardiomyocyte mortality, and make SR $\mathrm{Ca}^{2+}$ release lower to ameliorate myocardial infarct size in ischemia-reperfusion rats $[18,19]$. The overload of $\left(\mathrm{Ca}^{2+}\right)$ i concentration also causes the dysfunction of mitochondrial, increases concentration of oxygen free radicals and leads to myocardial cell death. Furthermore, clinical AMI cause sympathetic activation and catecholamine levels to rise, while catecholamine can increase the influx of $\mathrm{Ca}^{2+}$ through PKA pathway by activating $\alpha$ and $\beta$ receptors $[20,21]$.

Some studies have demonstrated that Danshen and its components have effects on calcium channels in ventricular myocytes and coronary artery [22,23]. Similarly, ligustrazine, defined as a calcium antagonist, not only will it block the entry of extracellular calcium but it will also inhibit the release of intracellular calcium. Moreover, it can also open potassium channel to make calcium influx lower [24,25]. According to the results, we found that SGI can reduce DOX-induced H9c2 cells damage by decreasing $\mathrm{Ca}^{2+}$ overload in vitro. In order to verify such effect in vivo, we investigated its myocardial protective effect in the left anterior descending coronary artery occlusion-induced AMI injury experiment. The results shown that SGI significantly improved the activities of $\mathrm{Ca}^{2+}$ related enzymes and decreased the mRNA expression of CaM and CaMK I/ in a dose-dependent manner.

The results indicate that SGI might protect cardiomyocytes from AMI injury by decreasing $\left(\mathrm{Ca}^{2+}\right) \mathrm{i}$ overload through inhibiting $\mathrm{CaM} / \mathrm{CaMK}$ II pathway and improving the activities of $\mathrm{Ca}^{2+}$ $\mathrm{Mg}^{2+}$-ATPase and $\mathrm{Na}^{+}-\mathrm{K}^{+}-$ATPase.

\section{CONCLUSION}

SGI protects cardiomyocytes against AMI by decreasing the infarction size, ameliorating 
myocardial histopathological damage, improving the activities of $\mathrm{Ca}^{2+}-\mathrm{Mg}^{2+}-\mathrm{ATP}$ ase and $\mathrm{Na}^{+}-\mathrm{K}^{+}$ATPase, and reducing $\left(\mathrm{Ca}^{2+}\right) \mathrm{i}$ overload through inhibition of CaM/CaMK II pathway, This suggests that SGI may be a new clinical candidate for the therapy of myocardial infarction.

\section{DECLARATIONS}

\section{Acknowledgement}

This work was supported by a grant from National Natural Science Foundation of China (no. 81673634).

\section{Conflict of Interest}

No conflict of interest associated with this work.

\section{Contribution of Authors}

The authors declare that this work was done by the authors named in this article and all liabilities pertaining to claims relating to the content of this article will be borne by them.

\section{Open Access}

This is an Open Access article that uses a funding model which does not charge readers or their institutions for access and distributed under the terms of the Creative Commons Attribution License (http://creativecommons.org/licenses/by/ 4.0) and the Budapest Open Access Initiative (http://www.budapestopenaccessinitiative.org/rea d), which permit unrestricted use, distribution, and reproduction in any medium, provided the original work is properly credited.

\section{REFERENCES}

1. Collaborators MCOD. Global, regional, and national agesex specific all-cause and cause-specific mortality for 240 causes of death, 1990-2013: a systematic analysis for the Global Burden of Disease Study 2013. Lancet 2015; 385(9963): 117-171.

2. Lau J, Antman EM, Jimenezsilva J, Kupelnick B, Mosteller F, Chalmers TC. Cumulative meta-analysis of therapeutic trials for myocardial infarction. N Engl J Med 1992; 327(4): 248-254.

3. Yamamura $S$, Nakagawa $S$, Kawamura A. Overview of Randomized Trials of Angiotensin-Converting Enzyme Inhibitors on Mortality and Morbidity in Patients with Heart Failure. Jama 1995; 273(18): 1450-1456.

4. Potu C, Tulloch-Reid E, Baugh D, Madu E. Left ventricular thrombus in patients with acute myocardial infarction: Case report and Caribbean focused update. Aust Med J 2012; 5(3): 178-183.

5. Yu JH, Wang LY, Akinyi M, Li YH, Duan ZZ, Zhu Y, Fan GW. Danshensu protects isolated heart against ischemia reperfusion injury through activation of Akt/ERK1/2/Nrf2 signaling. Int J Clin Exp Med 2015; 8(9): 14793-14804.

6. Yin Y, Guan Y, Duan JL, Wei G, Zhu YR, Quan W, Guo C, Zhou D, Wang YH, Xi MM, et al. Cardioprotective effect of Danshensu against myocardial ischemia/reperfusion injury and inhibits apoptosis of H9c2 cardiomyocytes via Akt and ERK1/2 phosphorylation. Eur J Pharmacol 2013; 699(1-3): 219226.

7. Liu $X Y$, Liu H, Zeng ZW, Zhou WH, Liu JQ, He ZW. Pharmacokinetics of ligustrazine ethosome patch in rats and anti-myocardial ischemia and anti-ischemic reperfusion injury effect. Int $J$ Nanomedicine 2011; 6: 1391-1398.

8. Liu $X T$, Ren PW, Peng L, Kang DY, Zhang $T L$, Wen $S$, Hong $Q$, Yang WJ. Effectiveness and safety of ShenXiong glucose injection for acute ischemic stroke: a systematic review and GRADE approach. BMC Complement Altern Med 2016; 16(1): 68.

9. Zheng L, Dong YX, Xie YM, Zhang XH, Dong L, Li YJ. Safety evaluation of Shenxiong glucose injection. Chin Pharmacol Bull 2015; (6): 887-888.

10. Office of Laboratory Animal Welfare/National Institutes of Health. 2002. Public Health Service policy on human care and use of laboratory animals. National Institutes of Health, Bethesda, Maryland. Available from: http://grants.nih.gov/grants/olaw/references/phspol.htm.

11. Qin RA, Lin J, Li CY, Fu WJ, Huang CY, Yu XM, Lin H, Nie $H$. Study of the protective mechanisms of Compound Danshen Tablet (Fufang Danshen Pian) against myocardial ischemia/reperfusion injury via the Akt-eNOS signaling pathway in rats. J Ethnopharmacol 2014; 156: 190-198.

12. Lee ES, Ryu JH, Kim EJ, Kim GT, Cho YW, Park HJ, Tak $H M$, Han J, Kang D. Lamotrigine increases intracellular $\mathrm{Ca}(2+)$ levels and $\mathrm{Ca}(2+) / c a l m o d u l i n-d e p e n d e n t$ kinase II activation in mouse dorsal root ganglion neurones. Acta Physiol (Oxf) 2013; 207(2): 397-404.

13. Rizzuto $R$, De Stefani $D$, Raffaello $A$, Mammucari $C$. Mitochondria as sensors and regulators of calcium signalling. Nat Rev Mol Cell Biol 2012; 13(9): 566-578.

14. Williams GS, Boyman L, Lederer WJ. Mitochondrial calcium and the regulation of metabolism in the heart. $J$ Mol Cell Cardiol 2015; 78: 35-45.

15. Inserte J, Garciadorado D, Hernando V, Solersoler J. Calpain-mediated impairment of $\mathrm{Na}+/ K_{+}-A T P a s e$ activity during early reperfusion contributes to cell death after myocardial ischemia. Circ Res 2005; 97(97): 465473.

16. Hvalby O, Hemmings HC Jr., Paulsen O, Czernik AJ, Nairn AC, Godfraind JM, Jensen V, Raastad M, Storm $J F$, Andersen $P$, et al. Specificity of protein kinase inhibitor peptides and induction of long-term

Trop J Pharm Res, May 2017; 16(5): 1103 
potentiation. Proc Natl Acad Sci U S A 1994; 91(11): 4761-4765.

17. Braun AP, Schulman $H$. The multifunctional calcium/calmodulin-dependent protein kinase: from form to function. Annu Rev Physiol 1995; 57: 417-445.

18. Vila-Petroff $M$, Salas $M A$, Said $M$, Valverde $C A$, Sapia $L$, Portiansky E, Hajjar RJ, Kranias EG, MundinaWeilenmann C, Mattiazzi A. CaMKII inhibition protects against necrosis and apoptosis in irreversible ischemiareperfusion injury. Cardiovasc Res 2007; 73(4): 689698.

19. Bell JR, Curl CL, Ip WTK, Delbridge LMD. Ca2+/calmodulin-dependent protein kinase inhibition suppresses post-ischemic arrhythmogenesis and mediates sinus bradycardic recovery in reperfusion. Int $\mathrm{J}$ Cardiol 2012; 159(2): 112-118.

20. Zelis $R$, Moore R. Recent insights into the calcium channels. Circulation 1989; 80(6 Suppl): IV14-16.

21. Karlsberg RP, Cryer PE, Roberts R. Serial plasma catecholamine response early in the course of clinical acute myocardial infarction: relationship to infarct extent and mortality. Am Heart J 1981; 102(1): 24-29.

22. Lam FFY, Yeung JHK, Chan KM, Or PMY. Relaxant effects of danshen aqueous extract and its constituent danshensu on rat coronary artery are mediated by inhibition of calcium channels. Vascul Pharmacol 2007; 46(4): 271-277.

23. Gao YG, Zhang K, Zhu FL, Wu ZL, Chu X, Zhang $X$, Zhang $Y$, Zhang JP, Chu L. Salvia miltiorrhiza (Danshen) inhibits L-type calcium current and attenuates calcium transient and contractility in rat ventricular myocytes. J Ethnopharmacol 2014; 158PA: 397-403.

24. Pang PK, Shan JJ, Chiu KW. Tetramethylpyrazine, a calcium antagonist. Planta Med 1996; 62(5): 431-435.

25. Tsai CC, Lai TY, Huang WC, Yang T, Liu IM, Wong KL, Chan $P$, Cheng JT. Tetramethylpyrazine as potassium channel opener to lower calcium influx into cultured aortic smooth muscle cells. Planta Med 2003; 69(6): 557-558. 